\title{
Identification and characterisation of carnostatine (SAN9812), a potent and selective carnosinase (CN1) inhibitor with in vivo activity
}

\author{
Jiedong Qiu ${ }^{1}$. Sibylle J. Hauske ${ }^{1}$. Shiqi Zhang ${ }^{1}$ - Angelica Rodriguez-Niño ${ }^{1}$ Thomas Albrecht $^{1}$ - Diego O. Pastene ${ }^{1}$. \\ Jacob van den Born ${ }^{2} \cdot$ Harry van Goor ${ }^{3}$. Sven Ruf ${ }^{4} \cdot$ Markus Kohlmann $^{4} \cdot$ Michael Teufel $^{4,5} \cdot$ Bernhard K. Krämer $^{1,7}$. \\ Hans-Peter Hammes ${ }^{1,7} \cdot$ Verena Peters $^{6} \cdot$ Benito A. Yard ${ }^{1,7}$. Aimo Kannt ${ }^{4,8}$
}

Received: 20 February 2018 / Accepted: 5 June 2018 / Published online: 20 June 2018

(c) The Author(s) 2018

\begin{abstract}
Carnosinase 1 (CN1) has been postulated to be a susceptibility factor for developing diabetic nephropathy (DN). Although its major substrate, carnosine, is beneficial in rodent models of DN, translation of these findings to humans has been hampered by high CN1 activity in human serum resulting in rapid degradation of carnosine. To overcome this hurdle, we screened a protease-directed small-molecule library for inhibitors of human recombinant CN1. We identified SAN9812 as a potent and highly selective inhibitor of CN1 activity with a $K_{\mathrm{i}}$ of $11 \mathrm{nM}$. It also inhibited CN1 activity in human serum and serum of transgenic mice-overexpressing human CN1. Subcutaneous administration of $30 \mathrm{mg} / \mathrm{kg}$ SAN9812 led to a sustained reduction in circulating CN1 activity in human CN1 transgenic (TG) mice. Simultaneous administration of carnosine and SAN9812 increased carnosine levels in plasma and kidney by up to 100-fold compared to treatment-naïve CN1-overexpressing mice. To our knowledge, this is the first study reporting on a potent and selective CN1 inhibitor with in vivo activity. SAN9812, also called carnostatine, may be used to increase renal carnosine concentration as a potential therapeutic modality for renal diseases linked to glycoxidative conditions.
\end{abstract}

Keywords Diabetic nephropathies $\cdot$ Carnosine $\cdot$ Aminoacyl-histidine dipeptidase $\cdot$ Drug discovery

Handling Editor: B. de Courten.

Jiedong Qiu and Sibylle J. Hauske contributed equally to this work.

Electronic supplementary material The online version of this article (https://doi.org/10.1007/s00726-018-2601-z) contains supplementary material, which is available to authorized users.

Aimo Kannt

Aimo.Kannt@Sanofi.com

1 5th Medical Department, Universitätsklinikum Mannheim, Mannheim, Germany

2 Department of Nephrology, University Medical Centre Groningen, Groningen, Netherlands

3 Department of Pathology and Medical Biology, University Medical Centre Groningen, Groningen, Netherlands

4 Sanofi Research and Development, Frankfurt am Main, Germany

\section{Introduction}

The rising global prevalence of type 2 diabetes (T2D) is accompanied by an increase in diabetic complications, such as diabetic nephropathy (DN), the single most common cause of end-stage renal disease (ESRD). Despite our continuously evolving understanding of the pathogenesis of $\mathrm{DN}$ and potential interventions, the current standard of care has largely failed to achieve stable long-term results, and a

5 Present Address: Translational Medicine Oncology, Bayer Healthcare Pharmaceuticals, Whippany, NJ, USA

6 Centre for Paediatric and Adolescent Medicine, University of Heidelberg, Heidelberg, Germany

7 European Center for Angioscience, Mannheim, Germany

8 Institute of Experimental Pharmacology, Medical Faculty Mannheim, University of Heidelberg, Mannheim, Germany 
strong unmet need for novel and more efficacious therapies remains (de Zeeuw and Heerspink 2016).

Carnosine ( $\beta$-alanyl-L-histidine) is a physiological dipeptide first discovered in meat extract more than 100 years ago (Gulewitsch and Amiradžibi 1900). It is primarily found in skeletal muscle where its content can be as high as $2 \mathrm{~g} / \mathrm{kg}$ wet tissue or $0.2 \%$ of overall skeletal muscle mass (Boldyrev et al. 2013). It is also present in other tissues such as brain, kidney or spleen albeit at 10- to 100-fold lower concentrations (Kamal et al. 2009). Properties pertaining to the physiological roles of carnosine include its $\mathrm{pH}$-buffering capacity, scavenging of reactive oxygen species (ROS) and peroxyl radicals, metal-ion chelation and protection against advanced glycation and lipoxidation end products (AGE and ALE, Boldyrev et al. 2013). Notably, carnosine has also been demonstrated to reverse pre-formed glycated proteins (Seidler et al. 2004). In line with its role in muscle physiology, food supplements containing carnosine or its precursor beta-alanine improve exercise performance in untrained individuals (Hill et al. 2007) as well as in elite athletes (Van Thienen et al. 2009; Baguet et al. 2010). Due to its metalion chelating and anti-oxidative properties, carnosine can ameliorate transition metal-catalysed- or hyperglycaemiamediated oxidative stress which may occur in several (pathologic) conditions such as diabetes and its complications (Zhang et al. 2016). Apart from the nutritional intake, tissue carnosine concentration also depends on the activity of local carnosine synthase, an ATP-dependent enzyme, as shown for a variety of tissues, e.g., skeletal muscle, brain or kidney (Drozak et al. 2010; Peters et al. 2015).

Carnosinase (CN1, EC 3.4.13.20) is the major carnosinedegrading enzyme. The human gene was cloned in 2003 and identified as the gene encoding the secreted form of carnosinase (Teufel et al. 2003). By positional cloning in a large Turkish family affected by DN, the carnosine dipeptidase 1 gene (CNDP1) was identified as a susceptibility gene for developing DN (Vardarli et al. 2002; Janssen et al. 2005). The leucine repeat in the signal sequence of $C N D P 1$ gene is essential for $\mathrm{CN} 1$ secretion with the short allelic variant $(\mathrm{CTG})_{5}$ associated with low-serum $\mathrm{CN} 1$ concentrations. Importantly, patients with $\mathrm{T} 2 \mathrm{D}$ without $\mathrm{DN}$ are significantly more frequently homozygous for the $(\mathrm{CTG})_{5}$ allele (Freedman et al. 2007; Riedl et al. 2007; Alkhalaf et al. 2010; Peters et al. 2016). It was postulated that low CN1 activity might favour high circulating carnosine concentrations. Of note, in a carnosine or beta-alanine supplementation study in rats with diet-induced obesity, it was recently demonstrated that plasma rather than muscle carnosine is involved in ameliorating high-fat diet-induced lipoxidative and inflammatory stress (Stegen et al. 2015). Carnosine supplementation studies in murine models demonstrated therapeutic efficacy of carnosine to ameliorate diabetes and DN, as albuminuria and histological lesions were reduced after supplementation (Lee et al. 2005; Alhamdani et al. 2007; Sauerhöfer et al. 2007; Riedl et al. 2011; Aldini et al. 2011; Nagai et al. 2012; Peters et al. 2012; Albrecht et al. 2017).

However, rodents-with the exception of Syrian hamster-lack the signal peptide in the CN1 gene and consequently do not have $\mathrm{CN} 1$ in the circulation (Boldyrev et al. 2013). This results in increased carnosine levels after oral carnosine supplementation (Albrecht et al. 2017). In contrast, carnosine supplementation in humans leads only to a small increase in circulating carnosine because of its fast degradation by serum CN1 (Everaert et al. 2011). Because of this difference, extrapolation of rodent findings to humans is difficult. As T2D patients have even higher serum CN1 activity levels compared to healthy controls (Riedl et al. 2010), CN1 inhibition could be a potential strategy to increase the serum concentration of carnosine, especially in combination with carnosine supplementation. So far, this possibility has not been explored due to the lack of a specific $\mathrm{CN} 1$ inhibitor. Here, we describe the identification and characterisation of a potent and selective $\mathrm{CN} 1$ inhibitor, carnostatine, and its effect on serum CN1 activity and carnosine levels in serum and renal tissue after co-administration with carnosine.

\section{Results}

We screened a protease-directed small-molecule library containing 6080 compounds for inhibitors of human recombinant CN1 using a screening assay based on the detection of histidine generated by proteolytic cleavage of carnosine (supplementary methods). The human recombinant CNDP1 showed a $K_{\mathrm{m}}$ value of $190 \mu \mathrm{M}$ (supplementary figure 1 ), similar to the previously reported value of $175 \mu \mathrm{M}$ (Peters et al. 2010). The average $Z^{\prime}$ value ( \pm SD) of all 38 test plates was $0.85 \pm 0.06$ (supplementary figure 2 ), indicating that the assay was of excellent robustness (Zhang et al. 1999). Results are summarised in Fig. 1. In total, we identified 133 compounds with $>50 \%$ inhibition. These compounds were re-tested in duplicates (supplementary figure 3).

One of the most potent compounds identified was SAN9812 (Fig. 2), with an $\mathrm{IC}_{50}$ value of $18 \mathrm{nM}$ on human recombinant $\mathrm{CN} 1$ at a carnosine concentration of $200 \mu \mathrm{M}$, i.e., close to the $K_{\mathrm{m}}$ of $190 \mu \mathrm{M}$. SAN9812 was found to be a competitive inhibitor, showing a right-shift in its $\mathrm{IC}_{50}$ value with increasing carnosine concentration (Fig. 3a). The $K_{\mathrm{i}}$ value of SAN9812 was determined as $11 \mathrm{nM}$ (Fig. 3b). The synthesis of SAN9812 is described in supplementary figure 4 and supplementary methods.

The inhibitory activity of SAN9812 on human CN1 was confirmed in serum from TG mice-expressing human $\mathrm{CN} 1$ and serum from healthy human volunteers (Fig. 3c, d). $\mathrm{IC}_{50}$ values were determined as 650 and $340 \mathrm{nM}$, respectively, at a carnosine concentration of $0.2 \mathrm{mg} / \mathrm{ml}$ or 

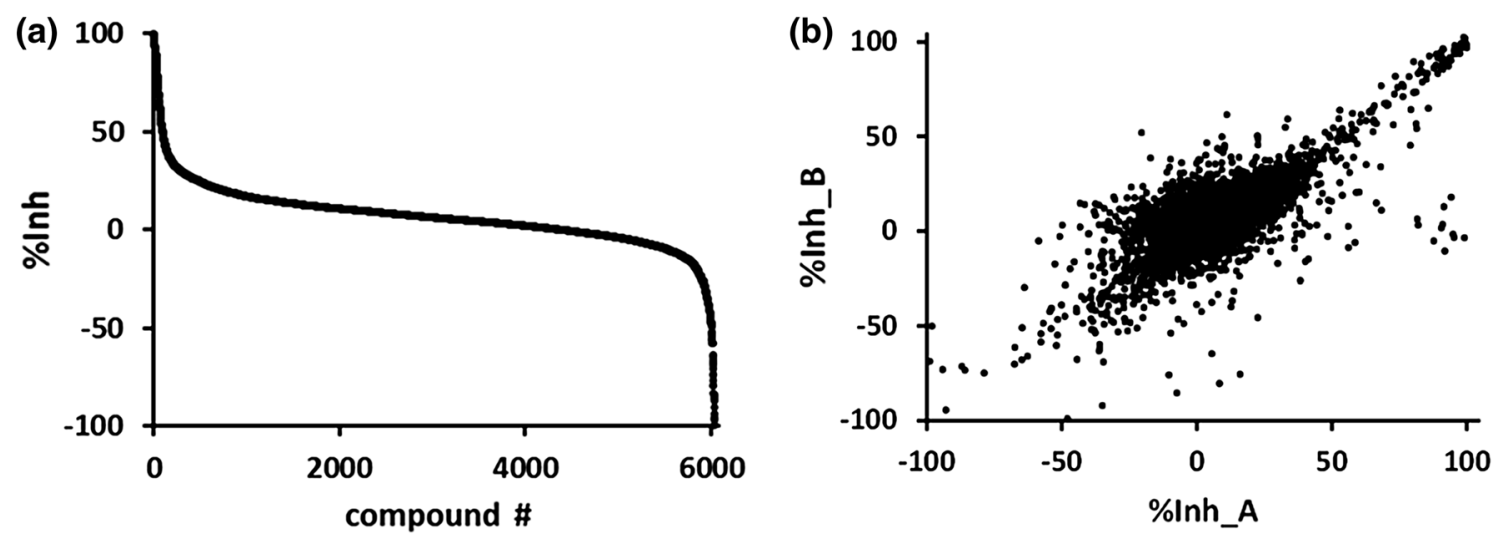

Fig. 1 a Distribution of mean percent-inhibition values in the screen of 6080 compounds for inhibitors of human recombinant CN1. b Comparison of percent-inhibition values obtained in duplicate experiments<smiles>NCCC(O)C(=O)NC(Cc1c[nH]cn1)C(=O)O</smiles>

Fig. 2 Structure of SAN9812

$880 \mu \mathrm{M}$. The average baseline hCN1 activities in transgenic mice and healthy human volunteers were $137 \pm 25$ and $1.1 \pm 0.25 \mu \mathrm{mol} / \mathrm{ml} / \mathrm{h}$, respectively.

Of note, SAN9812 was found to be inactive on a standard panel of 33 different receptors, channels, transporters and enzymes (supplementary Table 1) when tested at a concentration of $10 \mu \mathrm{M}$, reflecting overall selectivity of SAN9812 and ruling out that it is a modulator of a broad spectrum of biological activities. The ADME/PK (absorption, distribution, metabolism, excretion and pharmacokinetics) profile of SAN9812 is summarised in Table 1. The compound is very stable in human, rat and mouse liver microsomes and shows moderate clearance in primary human hepatocytes. Permeability in the CaCo-2 assay as a measurement of intestinal permeability was determined as $17.9 \mathrm{~nm} / \mathrm{s}$, indicating moderate oral absorption potential.

Plasma levels of SAN9812 after single bolus administration of either $3 \mathrm{mg} / \mathrm{kg}$ i.v. or $30 \mathrm{mg} / \mathrm{kg}$ s.c. are shown in Fig. 4a. Clearance, volume of distribution and subcutaneous bioavailability are summarised in Table 1 . After subcutaneous injection, maximal plasma concentrations were achieved already at the first sampling time point after administration (15 min). The maximal compound concentration after s.c. administration was $80 \mu \mathrm{g} / \mathrm{ml}$, corresponding to approximately $300 \mu \mathrm{M}$. Plasma levels quickly decrease to $30 \mu \mathrm{g} / \mathrm{ml}(120 \mu \mathrm{M})$ after $30 \mathrm{~min}$, $5.7 \mu \mathrm{g} / \mathrm{ml}(22 \mu \mathrm{M})$ after $1 \mathrm{~h}$, and $350 \mathrm{ng} / \mathrm{ml}(1.4 \mu \mathrm{M})$ after $2 \mathrm{~h}$. The lower level of quantification for the detection method was $10 \mathrm{ng} / \mathrm{ml}(40 \mathrm{nM})$. After intravenous injection, maximal plasma concentration was also observed at the first sampling time point, but there was a fast decrease in plasma SAN9812 concentrations reflecting rapid clearance of the compound from the circulation. Further experiments were performed using subcutaneous injection due to the longer availability of the compound in the blood.

In a subsequent pharmacodynamics study, $\mathrm{CN} 1$ activity was measured after a single subcutaneous bolus of $30 \mathrm{mg} /$ $\mathrm{kg}$ SAN9812, at the same time points as previously in the PK experiment. Results are shown in Fig. 4b, c. Animals were stratified according to their baseline serum carnosinase activity into a high-activity- ( $>250 \mu \mathrm{mol} / \mathrm{ml} / \mathrm{h})$ and a low-activity $(<45 \mu \mathrm{mol} / \mathrm{ml} / \mathrm{h})$ group. Mean baseline activities in the two groups were $259 \pm 13$ and $7.4 \pm 4.9 \mu \mathrm{mol} /$ $\mathrm{ml} / \mathrm{h}$, respectively. Administration of SAN9812 led to a rapid reduction in serum carnosinase activity by more than $90 \%$ in both groups which was sustained for $>8 \mathrm{~h}$. At the last sampling time point $16 \mathrm{~h}$ after compound administration, serum carnosinase activity was still reduced by $40 \%$ in the low-activity group and by $75 \%$ in the high-activity group.

SAN9812 was then subcutaneously administered over 7 days once daily at a dose of $30 \mathrm{mg} / \mathrm{kg}$. Blood samples were taken on days 1, 4 and 7 before, 6 and $12 \mathrm{~h}$ after the injection to measure $\mathrm{CN} 1$ activity. The results are depicted in Fig. 5. Again, CN1 activity was strongly and rapidly reduced after the first SAN9812 injection on day 1 and remained low over a period of $>12 \mathrm{~h}$. Importantly, baseline $\mathrm{CN} 1$ activities on days 4 and 7, measured $24 \mathrm{~h}$ after the previous SAN9812 administration on days 3 and 6 , respectively, were considerably lower compared to $\mathrm{CN} 1$ activity on day 1 before the 

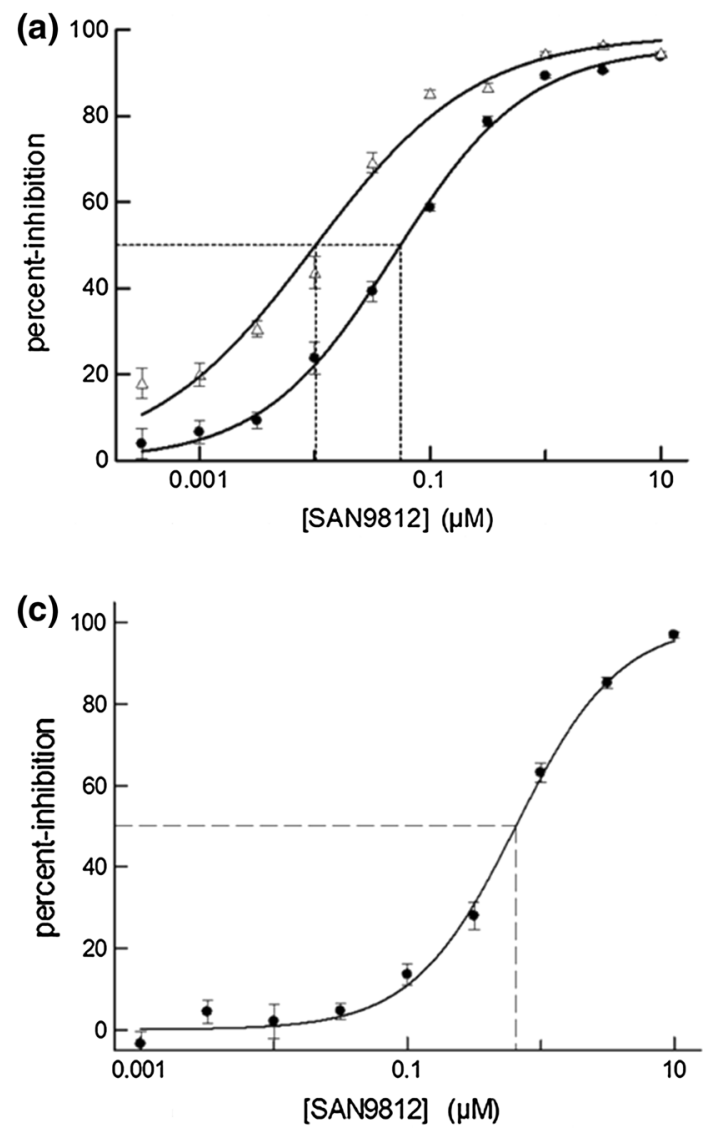

Fig. 3 a Concentration-response curves for SAN9812 determined at $100 \mu \mathrm{M}$ (open triangles) and $1000 \mu \mathrm{M}$ (filled squares) carnosine with human recombinant $\mathrm{CN} 1$ in $\mathrm{PBS}\left(n=6\right.$ each), corresponding $\mathrm{IC}_{50}$ values were determined as 10 and $54 \mathrm{nM}$, respectively. b Dependence of SAN9812 $\mathrm{IC}_{50}$ values on carnosine concentration ( $n=6$ each). The $K_{\mathrm{i}}$ values defined as the intersection of the linear regression line

Table 1 ADME and PK profile of SAN9812
Metabolic stability $h / r / m$ microsomes (\% remaining)

Human hepatocyte clearance $\left(\mathrm{ml} / \mathrm{h} / 10^{6}\right.$ cells $)$

Caco-2 permeability $(\mathrm{nm} / \mathrm{s})$

Clearance $(\mathrm{mL} / \mathrm{min} / \mathrm{kg})$

Volume of distribution $(\mathrm{L} / \mathrm{kg})$

Subcutaneous bioavailability (\%)

Selectivity panel

${ }^{a}$ At a concentration of $10 \mu \mathrm{M}$ vs a panel of 33 diverse receptors, ion channels, transporters and enzymes

first injection, indicating sustained carnosinase inhibition over $24 \mathrm{~h}$ in both the low-activity and high-activity groups.

The same average inhibition in percent was achieved in the group with low-baseline activity as in the group with high-baseline activity. In mice with low-baseline activity, CN1 activity was efficaciously inhibited over the whole observation period with an activity level kept
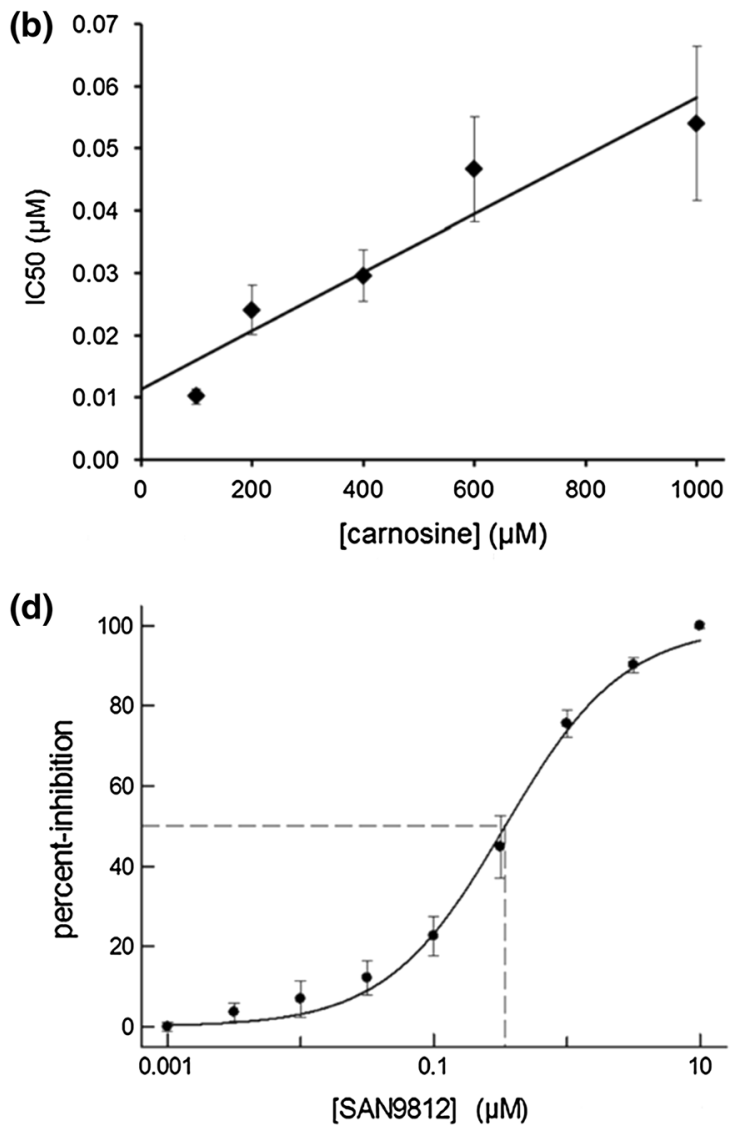

$\left(R^{2}=0.91\right)$ with the $y$-axis was determined as $11 \mathrm{nM}$. c Concentration-response curve of SAN9812 in serum from transgenic miceexpressing human $\mathrm{CN} 1$ (three replicates from three mice), and $\mathbf{d}$ in human serum (three replicates from two subjects) at a carnosine concentration of $880 \mu \mathrm{M}(0.2 \mathrm{mg} / \mathrm{ml}) . \mathrm{IC}_{50}$ values were determined as 650 and $340 \mathrm{nM}$, respectively. Data are presented as mean \pm SEM below $10 \mu \mathrm{mol} / \mathrm{ml} / \mathrm{h}$. In the group with high-baseline activity levels, absolute CN1 activity could sometimes exceed $100 \mu \mathrm{mol} / \mathrm{ml} / \mathrm{h}$ between injections, although percent-inhibition values were comparable in all animals (Fig. 5).

We did not note any obvious adverse effects of treatment with SAN9812 over 7 days, body weight and blood glucose were not different between treated and untreated animals.

To determine whether serum CN1 inhibition by SAN9812 can increase carnosine concentration in vivo in hCN1 overexpressing mice, animals were given a single bolus of $200 \mathrm{mg}$ carnosine alone or in combination with $30 \mathrm{mg} / \mathrm{kg}$ SAN9812 per s.c. injection. Plasma samples were taken 4 and $8 \mathrm{~h}$ after injection. Kidneys were harvested $8 \mathrm{~h}$ after injection. CN1-negative wild type mice and hCN1 mice without treatment served as controls.

Compared to wild type animals, hCN1 TG mice had significantly lower plasma carnosine levels (Fig. 6a, b). A similar, but non-significant trend was also seen for the kidney (Fig. 6c). As shown in Fig. 6a, in hCN1 mice after a single 


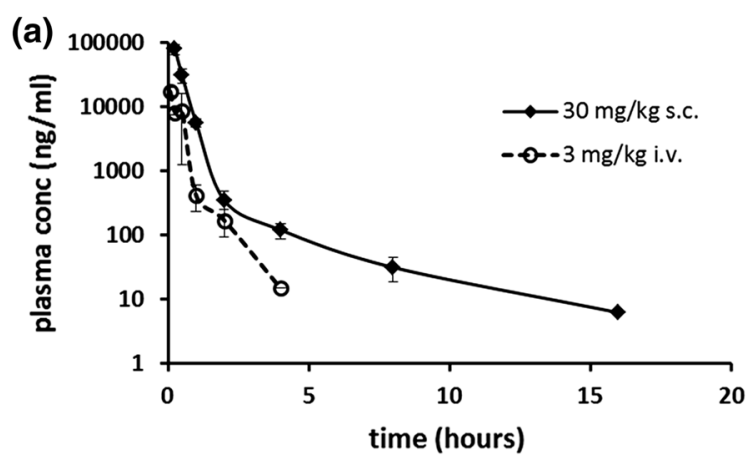

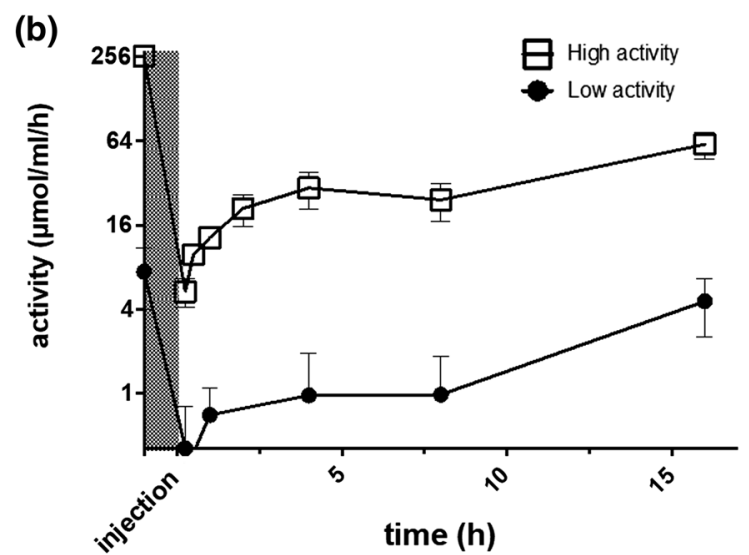

Fig. 4 a Plasma levels of SAN9812 after single bolus administration of either $3 \mathrm{mg} / \mathrm{kg}$ i.v. or $30 \mathrm{mg} / \mathrm{kg}$ s.c. ( $n=3$ each). The lower level of quantification for the detection method was $10 \mathrm{ng} / \mathrm{ml}(40 \mathrm{nM})$. Data are shown as mean \pm standard deviation. b, c Serum carnosinase activity before and after a single s.c. bolus injection of $30 \mathrm{mg} /$

subcutaneous bolus of carnosine, the plasma carnosine concentration increased compared to hCN1-overexpressing controls without carnosine administration $(p=0.049) 4 \mathrm{~h}$ after injection but was still lower compared to wild type mice without injection $(p=0.058)$. In contrast, a concurrent administration of carnosine and SAN9812 led to a further increase in carnosine plasma concentration, up to the levels of hCN1-negative controls without injection $4 \mathrm{~h}$ after administration. $8 \mathrm{~h}$ after concurrent administration of carnosine and SAN9812, plasma carnosine levels had returned to levels of hCN1 controls probably due to residual $\mathrm{CN} 1$ activity (mean \pm SD $14.4 \pm 15.7 \mu \mathrm{mol} / \mathrm{ml} / \mathrm{h}$ ). Mean CN1 activity in hCN1 mice was $55.3 \pm 30.6 \mu \mathrm{mol} / \mathrm{ml} / \mathrm{h}$.

As shown in Fig. 6c, in the kidney concurrent administration of carnosine and SAN9812 significantly increased carnosine concentration (mean $\pm \mathrm{SD} 3.5 \pm 2.3 \mathrm{nmol} /$ $\mathrm{mg}$ ) compared to wild type controls without any treatment $(0.32 \pm 0.46 \mathrm{nmol} / \mathrm{mg})$, hCN1-overexpressing mice $(0.034 \pm 0.028 \mathrm{nmol} / \mathrm{mg})$ and also hCN1-overexpressing mice supplemented with carnosine $(0.52 \pm 1.2)(p<0.005)$. Of note, kidneys were removed $8 \mathrm{~h}$ after injection when plasma carnosine levels had already returned to normal.

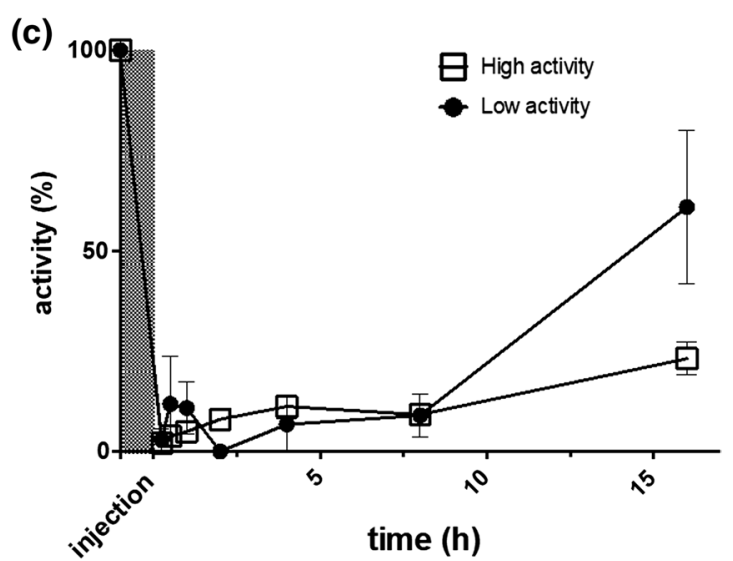

$\mathrm{kg}$ SAN9812. Absolute activities are shown in $\mathbf{b}$ for mice with lowserum carnosinase activity $(<45 \mu \mathrm{mol} / \mathrm{ml} / \mathrm{min}, n=3)$ or high-serum carnosinase activity $(>250 \mu \mathrm{mol} / \mathrm{ml} / \mathrm{min}, n=3)$. Percent-activity values from the same set of experiments are shown in (c). Data are depicted as mean \pm SEM

\section{Discussion}

In this work, we discovered carnostatine (SAN9812) as a potent and selective CN1 inhibitor with a $K_{\mathrm{i}}$ of $11 \mathrm{nM}$ for human recombinant CN1. Subcutaneous injection of SAN9812 led to a sustained reduction in serum carnosinase activity in transgenic mice overexpressing human $\mathrm{CN} 1$, both acutely as well as upon subchronic treatment. Additionally, a combination of carnosine and carnostatine caused a further increase in serum carnosine concentration and, for a disease such as DN most importantly, an increase of carnosine levels in renal tissue.

Carnosinase 1 has attracted considerable interest through the discovery in humans that a polymorphism of $\mathrm{CN} 1$ associated with lower serum $\mathrm{CN} 1$ concentrations protects against DN. In keeping with the hypothesis that low serum $\mathrm{CN} 1$ concentration may protect patients with type 2 diabetes from developing DN, the rationale of the current study was to generate a potent $\mathrm{CN} 1$ inhibitor as a potential drug candidate for preventing or slowing down the progression of DN.

The protective effect of a genotype with lower CN1 activity, as shown in large cross-sectional studies, is likely 


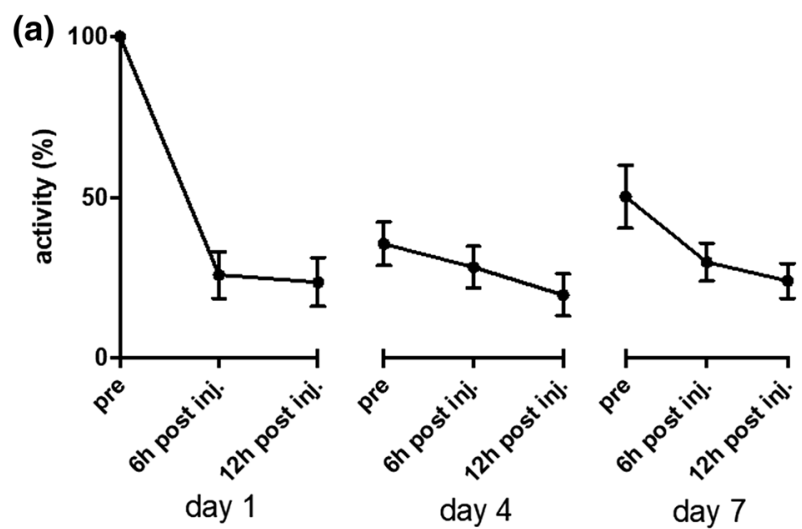

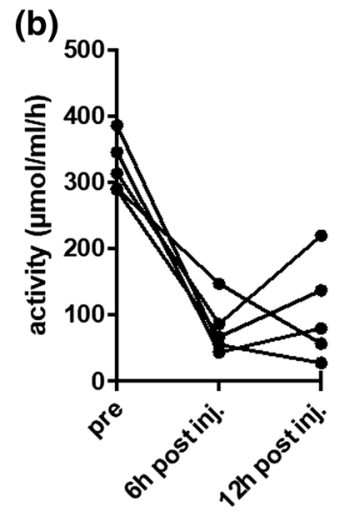

day 1

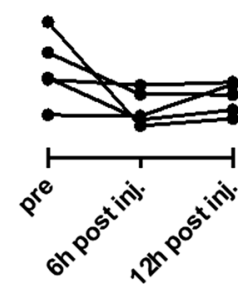

day 4

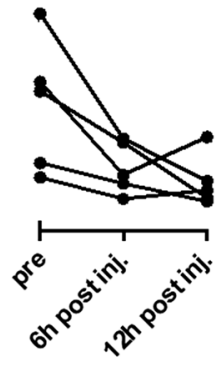

day 7
Fig. 5 Subchronic (7 days) administration of SAN9812 (30 mg/ $\mathrm{kg}$ s.c. q.d.) inhibits serum $\mathrm{CN} 1$ activity. a Serum CN1 activity (relative to day 1 baseline) prior to, 6 and $12 \mathrm{~h}$ after compound administration on days 1,4 or 7 for all mice investigated $(n=10$,

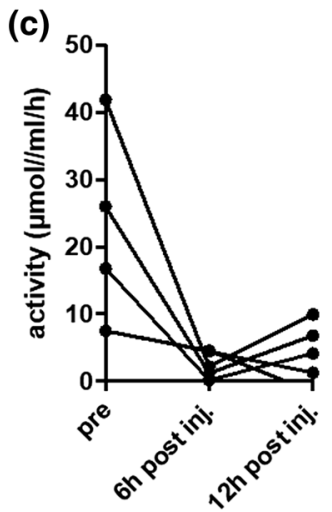

day 1

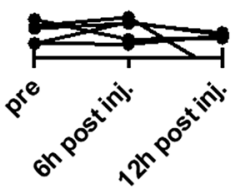

day 4

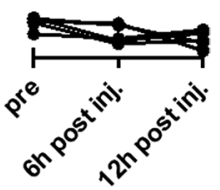

day 7

mean $\pm \mathrm{SEM})$. b, c Individual absolute $\mathrm{CN} 1$ activities for the highactivity $(\mathbf{b}, n=5)$ and the low-activity $(\mathbf{c}, n=5)$ group of hCN1expressing transgenic mice

(a)

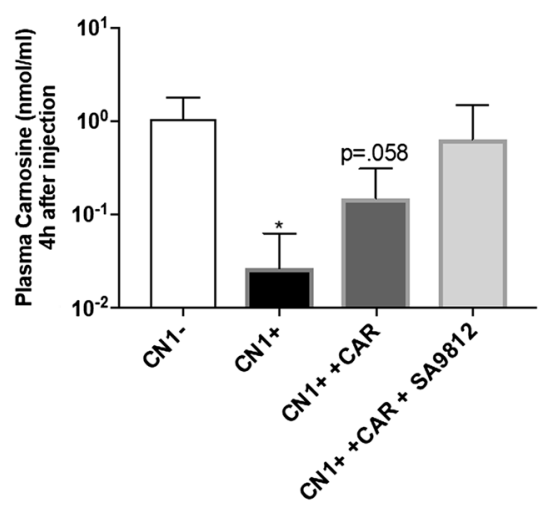

Fig. 6 Plasma and renal tissue carnosine concentration upon subcutaneous carnosine supplementation (CAR) with and without SAN9812 administration in hCN1 overexpressing (CN1+) mice ( $n=5-8$ per group). hCN1-negative wild type mice $(\mathrm{CN} 1-)$ served as controls. The lower level of quantification for the detection method was $0.0001 \mathrm{nmol} / \mathrm{mg}$. Data are shown as mean $\pm \mathrm{SD}$. a Plasma car- (c)

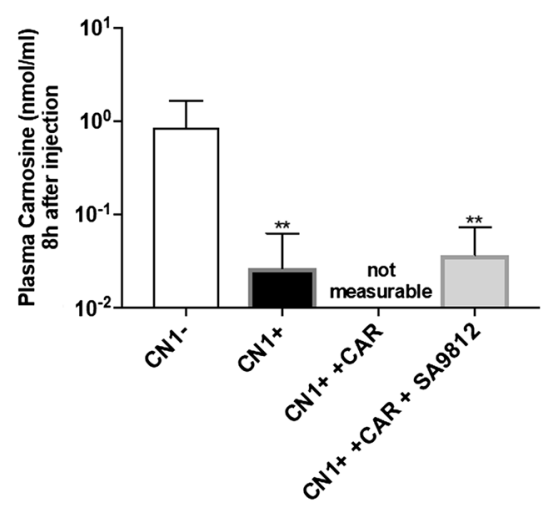

nosine concentration $4 \mathrm{~h}$ and $\mathbf{b} 8 \mathrm{~h}$ after administration of carnosine \pm SAN9812. c Carnosine concentration in the kidney harvested $8 \mathrm{~h}$ after injection. One-way ANOVA followed by Dunnett's multiple comparisons test was performed using GraphPad Prism $(* p<0.05$, ** for $p<0.01$ ) 
mediated by an increase in serum carnosine concentration. To increase serum carnosine, many carnosine supplementation studies have been conducted in rodent models. However, as rodents lack the signal peptide in the $\mathrm{CN} 1$ gene and consequently do not have $\mathrm{CN} 1$ in the circulation (Boldyrev et al. 2013), the translation of these findings to humans is difficult. Unlike rodents, humans have considerable serum $\mathrm{CN} 1$ activity which may even be higher in particular disease states, e.g., in diabetic individuals compared to healthy controls (Riedl et al. 2010). Thus, as observed in healthy volunteers, carnosine supplementation only leads to a moderate increase in plasma carnosine for a limited period of time between 1 and $2 \mathrm{~h}$ because of its rapid degradation by CN1 (Everaert et al. 2012) that may markedly limit carnosine's beneficial effects in humans.

Several human trials in the field of sports medicine have been conducted, either with carnosine or beta-alanine, the rate-limiting precursor for endogenous carnosine synthesis, and showed beneficial effects on exercise performance (Hill et al. 2007; Van Thienen et al. 2009; Baguet et al. 2010). Although muscle carnosine was not measured in our study, the marked increase by 100 -fold in renal tissue concentration of carnosine by simultaneous administration of carnosine and a CN1-specific inhibitor, although in an artificial setting, was promising and suggests that our approach may also enhance the beneficial effects of carnosine in other tissues.

Other human trials have shown a positive effect of carnosine supplementation on insulin sensitivity in obese human individuals (De Courten et al. 2016; Regazzoni et al. 2016). Because of the reasons given above, an additional CN1 inhibition may further increase these beneficial effects. So far, this has not been studied because of the lack of a specific CN1 inhibitor. Here, we describe SAN9812, a specific CN1 inhibitor as a new tool for such studies. As SAN9812 can stabilise carnosine levels both in plasma and kidney tissue after co-administration with carnosine, we propose to use the name carnostatine for SAN9812.

In the current work, carnostatine and carnosine were subcutaneously injected. The oral availability of carnostatine has so far not been investigated. Oral absorption potential of carnostatine, based on Caco-2 permeability, was found to be moderate but high enough to merit additional studies where the compound could be given via oral gavage or drinking water. Especially the latter option would make it feasible to perform chronic treatment studies with minimal compound application stress for the study animals.

Possible side effects of carnostatine could be similar to carnosinemia, where a lack of carnosinase is associated with several neurological symptoms. Although we could not detect any major side effects after 7 days of carnostatine treatment in mice, we could not exclude any neurological symptoms since no behaviour test was performed.
Moreover, $\mathrm{CN} 1$ is postulated to play a major role in brain gamma-aminobutyric acid (GABA)-ergic system as it can release GABA by degrading homocarnosine. If carnostatine can bypass the blood-brain-barrier, it could interfere with this system and cause GABA-deficiency symptoms such as depression, anxiety or panic. In addition, pathways involving other degradation products of $\mathrm{CN} 1$, e.g., histidine or beta-alanine could be influenced.

The model system used in our study-mice-overexpressing human $\mathrm{CN} 1$-is reflecting the situation in humans where plasma carnosinase activity can be detected. However, the model also has certain limitations, such as the high variability of $\mathrm{CN} 1$ activity and a high absolute plasma $\mathrm{CN} 1$ activity compared to lean human volunteers. Thus, care should be taken to stratify animal according to CN1 activity and to select animals with moderately increased $\mathrm{CN} 1$ activity for further chronic studies.

To our knowledge, this is the first in vivo active carnosinase inhibitor described. This CN1 inhibitor is potent with a $K_{\mathrm{i}}$ of $11 \mathrm{~nm}$ and specific with no reactivity vs. a panel of 33 different receptors, channel transporters and enzymes. So far, our studies were limited to healthy animals and short treatment periods. It will be interesting to see whether chronic carnosinase inhibition, especially if carnostatine is orally administered in combination with carnosine, can protect from diabetic nephropathy as seen in carnosine supplementation studies in mice devoid of plasma CN1 activity. Such studies are currently underway.

\section{Methods}

\section{Subjects (mice, human)}

\section{Mice}

Human CNDP1 transgenic mice on a BTBR wt/ob background (Jackson Laboratory Stock number: 004824) were used for the experiments. These mice express human CN1 in brain and liver from where it is secreted into the blood. The generation and characterisation of these hCN1 overexpressing mice will be described in a separate paper. The animals were housed in a 12 -h light/dark cycle at $22{ }^{\circ} \mathrm{C}$ and sacrificed under isoflurane anaesthesia by neck dislocation. Animals between 8 and 10 weeks of age with a body weight of 25-35 g were used. For the experiment with carnosine \pm carnostatine injection age- and sexmatched animals were used. Body weight and blood glucose were measured between the injections to detect major abnormalities of animal well-being. No difference between two groups was detected. 
Human

Serum samples were taken from two healthy donors (one male, one female) that were 25 and 26 years of age, respectively.

\section{High-throughput screening and compound characterisation}

We screened a protease-directed small compound library using human recombinant carnosinase 1 based on an assay described by Teufel 2002. Details are described in supplementary methods. $\mathrm{IC}_{50}$ and $K_{\mathrm{i}}$ values and the mode of inhibition by SAN9812 were determined as described in supplementary methods. Activity of SAN9812 on a standard panel of 33 different receptors, channels, transporters and enzymes was measured at Eurofins Pharma Discovery Services. Detailed descriptions of individual assays can be found at https://www.eurofinsdiscoveryservices.com.

\section{Activity of SAN9812 in human and mouse serum}

To determine the concentration-response curve of SAN9812, serum from two healthy donors and three CN1transgenic mice were used. SAN9812 was diluted with PBS and added to the serum directly (2-3 s) before measuring the $\mathrm{CN} 1$ activity.

\section{ADME profile of SAN9812}

A detailed description of the methods used to investigate the ADME profile can be found in the supplementary methods.

\section{Pharmacokinetics}

Pharmacokinetic parameters were determined in female C57BL/6 mice (Harlan, Germany). After a single administration of either $3 \mathrm{mg} / \mathrm{kg}$ i.v. or $30 \mathrm{mg} / \mathrm{kg}$ s.c. of test compound dissolved in phosphate-buffered saline, $\mathrm{pH} 7.4$, plasma samples were taken at eight time points over $24 \mathrm{~h}$. Three animals per time point were used. Concentrations of the test compound were determined with an exploratory LC-MS/MS method using an internal standard. Clearance and volume of distribution were determined based on the i.v. pharmacokinetics, subcutaneous bioavailability by comparing the area under the curve after subcutaneous vs. intravenous administration. Pharmacokinetic parameters were calculated using the program WinNonlin 6.4 (Pharsight
Corporation) assuming a non-compartmental model and linear trapezoidal interpolation.

\section{Pharmacodynamics}

The mice are injected with $30 \mathrm{mg} / \mathrm{kg}$ SAN9812 in a $0.9 \%$ $\mathrm{NaCl}$ solution subcutaneously. Before and after the injection blood was taken at different time points. The blood samples were incubated for $30 \mathrm{~min}$ at room temperature before being centrifuged at $2500 \mathrm{~g}$ for $10 \mathrm{~min}$. The supernatant as serum was used afterwards to determine the CN1 activity. Two groups of animals with three animals each were used, one with activity levels all below $45 \mu \mathrm{mol} /(\mathrm{ml} \mathrm{h})$ defined as the low-activity group and one with activity levels all above $250 \mu \mathrm{mol} /(\mathrm{ml} \mathrm{h})$ defined as high-activity group. These two groups are depicted separately in the figures.

\section{Pharmacodynamics upon subchronic administration}

The mice were treated with $30 \mathrm{mg} / \mathrm{kg}$ SAN9812 in a $0.9 \%$ $\mathrm{NaCl}$ solution for 1 week by daily subcutaneous injection. Before and after the compound administration serum was taken and CN1 activity was measured. Animals were stratified to high- and low-activity groups as described above and five mice per group were used.

\section{Acute carnosine injection \pm SAN9812 in mice}

Carnosinase 1-overexpressing mice were supplemented with a bolus of $200 \mathrm{mg}$ carnosine alone or in combination with $30 \mathrm{mg} / \mathrm{kg}$ SAN9812 in a $0.9 \% \mathrm{NaCl}$ solution by s.c. administration. hCN1-negative and hCN1-overexpressing mice served as controls $(n=5-8)$. Plasma samples were taken after $4 \mathrm{~h}$ and after $8 \mathrm{~h}$. After $8 \mathrm{~h}$, mice were sacrificed and kidneys were harvested.

\section{Chemical analyses}

A more extended description of chemical analyses can be found in the supplementary methods.

\section{Sample preparation}

Serum and EDTA plasma were taken according to standard protocols. For CN1, activity serum was taken, for carnosine measurement, EDTA plasma and tissue samples supplemented with 2 mmol EDTA were used.

\section{CN1 activity}

Carnosinase 1 activity was measured using a modified protocol based on the assay described by Teufel 2002. Details are in the supplementary methods. 


\section{Carnosine concentration}

Carnosine concentration was measured by high-performance liquid chromatography as previously described (Schönherr 2002).

\section{Figures and statistics}

Figures were created using Microsoft Excel and GraphPad Prism 7.0. Error bars denote either standard deviation (SD) or standard error of the mean (SEM) as described in the individual figure legends. To compare different groups, ANOVA one-way with Holm-Sidak's multiple comparison test were applied using GraphPad Prism 7.0.

Acknowledgements Karen Bieback, Claire Kammermeier, Kristina Klingbeil and Martin Stephan are acknowledged for excellent technical assistance. Research support was received from the International Research and Training Network on Diabetic Microvascular Complications (GRK1874/DIAMICOM; J.Q., S.Z., A.R.-N., T.A., J.vdB., H.vG., B.K.K., H-P.H., B.A.Y.)

Funding This research was supported by the German Research Foundation DFG, the graduate school GRK1874 (Diabetic Microvascular Complications), collaborative research centre (SFB 1118), Medical Faculty Mannheim of University Heidelberg (SabIne Fellowship) and Sanofi Aventis Deutschland GmbH.

\section{Compliance with ethical standards}

Conflict of interest AK., S.R. and M.T. are or were employees of Sanofi Aventis Deutschland GmbH.

Ethical approval All procedures performed in studies involving animals were in accordance with the ethical standards of the institution or practice at which the studies were conducted. The experiments were approved by the local Ethical Committee.

Open Access This article is distributed under the terms of the Creative Commons Attribution 4.0 International License (http://creativeco mmons.org/licenses/by/4.0/), which permits unrestricted use, distribution, and reproduction in any medium, provided you give appropriate credit to the original author(s) and the source, provide a link to the Creative Commons license, and indicate if changes were made.

\section{References}

Albrecht T, Schilperoort M, Zhang S et al (2017) Carnosine attenuates the development of both type 2 diabetes and diabetic nephropathy in BTBR ob/ob mice. Sci Rep 7:44492. https:// doi.org/10.1038/srep44492

Aldini G, Orioli M, Rossoni G et al (2011) The carbonyl scavenger carnosine ameliorates dyslipidemia and renal function in Zucker obese rats. J Cell Mol Med 15:1339-1354. https://doi.org/10.1 111/j.1582-4934.2010.01101.x
Alhamdani MSS, Al-Kassir AHAM, Abbas FKH et al (2007) Antiglycation and antioxidant effect of carnosine against glucose degradation products in peritoneal mesothelial cells. Nephron Clin Pract 107:1660-2110. https://doi.org/10.1159/000106509

Alkhalaf A, Bakker SJL, Bilo HJG et al (2010) A polymorphism in the gene encoding carnosinase (CNDP1) as a predictor of mortality and progression from nephropathy to end-stage renal disease in type 1 diabetes mellitus. Diabetologia 53:2562-2568. https://doi.org/10.1007/s00125-010-1863-0

Baguet A, Bourgois J, Vanhee L et al (2010) Important role of muscle carnosine in rowing performance. J Appl Physiol 109:10961101. https://doi.org/10.1152/japplphysiol.00141.2010

Boldyrev AA, Aldini G, Derave W (2013) Physiology and pathophysiology of carnosine. Physiol Rev 93:1803-1845. https:// doi.org/10.1152/physrev.00039.2012

De Courten B, Jakubova M, De Courten MPJ et al (2016) Effects of carnosine supplementation on glucose metabolism: pilot clinical trial. Obesity 24:1027-1034. https://doi.org/10.1002/oby.21434

de Zeeuw D, Heerspink HJL (2016) Unmet need in diabetic nephropathy: failed drugs or trials? Lancet Diabetes Endocrinol 4:638640. https://doi.org/10.1016/S2213-8587(16)30045-6

Drozak J, Veiga-da-Cunha M, Vertommen D et al (2010) Molecular identification of carnosine synthase as ATP-grasp domaincontaining protein 1 (ATPGD1). J Biol Chem 285:9346-9356. https://doi.org/10.1074/jbc.M109.095505

Everaert I, Mooyaart A, Baguet A et al (2011) Vegetarianism, female gender and increasing age, but not CNDP1 genotype, are associated with reduced muscle carnosine levels in humans. Amino Acids 40:1221-1229. https://doi.org/10.1007/s0072 6-010-0749-2

Everaert I, Taes Y, De Heer E et al (2012) Low plasma carnosinase activity promotes carnosinemia after carnosine ingestion in humans. AJP Ren Physiol 302:F1537-F1544. https://doi. org/10.1152/ajprenal.00084.2012

Freedman BI, Hicks PJ, Sale MM et al (2007) A leucine repeat in the carnosinase gene CNDP1 is associated with diabetic end-stage renal disease in European Americans. Nephrol Dial Transplant 22:1131-1135. https://doi.org/10.1093/ndt/gfl717

Gulewitsch W, Amiradžibi S (1900) Ueber das Carnosin, eine neue organische Base des Fleischextractes. Berichte der Dtsch Chem Gesellschaft 33:1902-1903. https://doi.org/10.1002/cber.19000 330275

Hill CA, Harris RC, Kim HJ et al (2007) Influence of $\beta$-alanine supplementation on skeletal muscle carnosine concentrations and high intensity cycling capacity. Amino Acids 32:225-233. https ://doi.org/10.1007/s00726-006-0364-4

Janssen B, Hohenadel D, Brinkkoetter P et al (2005) Carnosine as a protective factor in diabetic nephropathy: association with a leucine repeat of the carnosinase gene CNDP1. Diabetes 54:2320-2327. https://doi.org/10.2337/diabetes.54.8.2320

Kamal MA, Jiang H, Hu Y et al (2009) Influence of genetic knockout of Pept 2 on the in vivo disposition of endogenous and exogenous carnosine in wild-type and Pept 2 null mice. Am J Physiol Regul Integr Comp Physiol 296:R986-R991. https:// doi.org/10.1152/ajpregu.90744.2008

Lee YT, Hsu CC, Lin MH et al (2005) Histidine and carnosine delay diabetic deterioration in mice and protect human low density lipoprotein against oxidation and glycation. Eur J Pharmacol 513:145-150. https://doi.org/10.1016/j.ejphar.2005.02.010

Nagai K, Tanida M, Niijima A et al (2012) Role of L-carnosine in the control of blood glucose, blood pressure, thermogenesis, and lipolysis by autonomic nerves in rats: involvement of the circadian clock and histamine. Amino Acids 43:97-109. https ://doi.org/10.1007/s00726-012-1251-9

Peters V, Kebbewar M, Jansen EW et al (2010) Relevance of allosteric conformations and homocarnosine concentration on 
carnosinase activity. Amino Acids 38:1607-1615. https://doi. org/10.1007/s00726-009-0367-z

Peters V, Schmitt CP, Zschocke J et al (2012) Carnosine treatment largely prevents alterations of renal carnosine metabolism in diabetic mice. Amino Acids 42:2411-2416. https://doi. org/10.1007/s00726-011-1046-4

Peters V, Klessens CQF, Baelde HJ et al (2015) Intrinsic carnosine metabolism in the human kidney. Amino Acids. https://doi. org/10.1007/s00726-015-2045-7

Peters V, Kebbewar M, Janssen B et al (2016) CNDP1 genotype and renal survival in pediatric nephropathies. J Pediatr Endocrinol Metab 29:827-833. https://doi.org/10.1515/jpem-2015-0262

Regazzoni L, de Courten B, Garzon D et al (2016) A carnosine intervention study in overweight human volunteers: bioavailability and reactive carbonyl species sequestering effect. Sci Rep 6:27224. https://doi.org/10.1038/srep27224

Riedl E, Koeppel H, Brinkkoetter P et al (2007) A CTG polymorphism in the CNDP1 gene determines the secretion of serum carnosinase in Cos-7 transfected cells. Diabetes 56:2410-2413. https://doi. org/10.2337/db07-0128

Riedl E, Koeppel H, Pfister F et al (2010) N-Glycosylation of carnosinase influences protein secretion and enzyme activity: implications for hyperglycemia. Diabetes 59:1984-1990. https://doi. org/10.2337/db09-0868

Riedl E, Pfister F, Braunagel M et al (2011) Carnosine prevents apoptosis of glomerular cells and podocyte loss in STZ diabetic rats. Cell Physiol Biochem 28:279-288. https://doi.org/10.1159/000331740

Sauerhöfer S, Yuan G, Braun GS et al (2007) L-Carnosine, a substrate of carnosinase-1, influences glucose metabolism. Diabetes 56:2425-2432. https://doi.org/10.2337/db07-0177

Schönherr J (2002) Analysis of products of animal origin in feeds by determination of carnosine and related dipeptides by high-performance liquid chromatography. J Agric Food Chem 50:1945-1950. https://doi.org/10.1021/jf0112116

Seidler NW, Yeargans GS, Morgan TG (2004) Carnosine disaggregates glycated alpha-crystallin: an in vitro study. Arch Biochem Biophys 427:110-115. https://doi.org/10.1016/j.abb.2004.04.024

Stegen S, Stegen B, Aldini G et al (2015) Plasma carnosine, but not muscle carnosine, attenuates high-fat diet-induced metabolic stress. Appl Physiol Nutr Metab 40:868-876. https://doi. org/10.1139/apnm-2015-0042

Teufel M, Saudek V, Ledig JP et al (2003) Sequence identification and characterization of human carnosinase and a closely related non-specific dipeptidase. J Biol Chem 278:6521-6531. https://doi. org/10.1074/jbc.M209764200

Van Thienen R, Van Proeyen K, Vanden Eynde B et al (2009) $\beta$-Alanine improves sprint performance in endurance cycling. Med Sci Sports Exerc 41:898-903. https://doi.org/10.1249/MSS.0b013 e31818db708

Vardarli I, Baier LJ, Hanson RL et al (2002) Gene for susceptibility to diabetic nephropathy in type 2 diabetes maps to 18q22.3-23. Kidney Int 62:2176-2183. https://doi.org/10.104 6/j.1523-1755.2002.00663.x

Zhang J-H, Chung TDY, Oldenburg KR (1999) A simple statistical parameter for use in evaluation and validation of high throughput screening assays. J Biomol Screen 4:67-73. https://doi. org/10.1177/108705719900400206

Zhang S, Ntasis E, Kabtni S et al (2016) Hyperglycemia does not affect iron mediated toxicity of cultured endothelial and renal tubular epithelial cells: influence of L-carnosine. J Diabetes Res. https:// doi.org/10.1155/2016/8710432 